\title{
Apresentação do dossiê: Usos do passado recente na América Latina
}

\author{
Natália Ayo Schmiedecke ${ }^{1}$ \\ Vanesa Garbero ${ }^{2}$
}

Se o passado sempre é uma construção, a partir das demandas do presente, esta relação é ainda mais evidente no caso de um passado recente, cujas consequências diretas têm fortes efeitos sobre o presente e cujos sentidos permanecem em disputa. Frente às violências e crimes de Estado que marcaram o século XX, a academia, impulsionada pelos coletivos afetados, assistiu a um crescimento exponencial das pesquisas que se comprometem com este passado. Tais estudos se circunscrevem na chamada história do tempo presente, imediata ou do presente, segundo as variáveis denominações nacionais. Trata-se de um campo que se consolidou na historiografia neste novo século, mas que já vinha se desenvolvendo e sendo problematizado desde a década de 1970, especialmente na ciência política e na sociologia (FRANCO, 2018).

A especificidade da história recente reside em um "regime de historicidade" (HARTOG, 2014) em que os fatos e processos do passado interpelam as sociedades contemporâneas na construção de identidades individuais e coletivas. Trata-se de um passado presente, de um "passado que não passa". Aqui as análises perdem o "ponto fixo" e fechado de um passado do qual seria possível aproximar-se com alguma "distância”, "objetividade” e "perspectiva", para se constituírem "em um diálogo e uma escuta atenta às demandas e interpelações que este passado formula ao presente, razão pela qual deixa de concebê-lo como fechado, finalizado" (PITTALUGA, 2010, p. 31). Este regime é relacional na medida em que confluem passado, presente e futuro (p. 31).

\footnotetext{
${ }^{1}$ Doutora em História, pós-doutoranda no Departamento de História do Instituto de Filosofia e Ciências Humanas da Universidade Estadual de Campinas. Pesquisa em andamento: "Cultura e socialismo: entre a Revolução Cubana e a Via chilena (1970-1973)", financiada pela FAPESP (processo n 2018/00325-0). E-mail: nati.ayo@ gmail.com.

${ }^{2}$ Doutora em Ciências Sociais pela Universidade de Buenos Aires. Professora do Centro de Estudos Avançados da Faculdade de Ciências Sociais da Universidade Nacional de Córdoba. E-mail: vanegarbero@yahoo.com.ar.
} 
Cada historiografia nacional tem particularidades que marcam o início deste campo de estudo. Há, porém, processos comuns que convergiram em seu desenvolvimento, entre os quais interessa destacar o da história oral e, em particular, os estudos da memória (FRANCO, 2018, p. 177). Estes últimos adquiriram a partir dos anos 1980 uma importância cada vez maior nas sociedades ocidentais, ativada principalmente pelos estudos sobre o Holocausto e seu uso como tropos universal do trauma histórico (HUYSSEN, 2007). Na segunda metade dos anos 1990, irromperam com força na Argentina e no Chile e foram se estendendo a outros países latinoamericanos com o intuito de processar as dramáticas consequências das ditaduras que flagelaram o Cone Sul.

Por "memória", entende-se o processo de construção, elaboração e (re)significação do passado (HALBWACHS, 2011; POLLAK, 2006; RICCEUR, 1999; JELIN, 2002). Segundo Halbwachs (2004; 2011), trata-se de uma reconstrução que se realiza no e a partir do presente e que encontra nele seus princípios de seleção, descrição e narração. Nas palavras de Jelin (2012, p. 43-44, grifado no original): "Falar de memória significa falar do presente. Na verdade, a memória não é passado, mas sim a maneira em que os sujeitos constroem um sentido do passado, um passado que ganha sentido em seu vínculo com o presente no ato de rememorar/esquecer; também em função de um futuro desejado”. Em relação a esses estudos, a história oral, que surge do seio da história social (ACEVES, 1993, p. 234), mostra-se uma ferramenta útil reconstruir processos socio-históricos a partir da percepção e concepção dos protagonistas, favorecendo a escritura da história dos oprimidos e esquecidos. Segundo Portelli (1991, p. 45), a riqueza da história oral "não está tanto em sua capacidade para preservar o passado como nas próprias mudanças elaboradas pela memória. Estas mudanças revelam o esforço dos narradores por dar um sentido ao passado e uma forma a suas vidas".

$\mathrm{Na}$ América Latina, o campo da história recente também recebeu impulso dos "processos políticos, lutas sociais e formas de elaboração e processamento coletivos do passado de extrema violência", "em um claro movimento do político ao profissional-científico" (FRANCO, 2018, p. 178). Isso influenciou para que o campo se constituísse sobre o problema da 
violência política e dos regimes ditatoriais. Não obstante, ele paulatinamente foi incorporando uma escala temporal de maior alcance, compreendendo os processos anteriores e posteriores, $\mathrm{e}$ temáticas diversas. Podemos mencionar como exemplos: a crescente atenção às "organizações, sujeitos e projetos políticos revolucionários e de esquerda que formaram parte de uma onda regional de desafios ao sistema em um contexto amplo de guerra fria e dentro do ciclo revolução/contrarrevolução - nos termos de Grandin” (FRANCO, 2018, p. 186); as políticas transicionais em torno à memória, verdade e justiça; as consequências econômicas, sociais e culturais dos regimes repressivos; e o surgimento e protagonismo dos movimentos da sociedade civil.

Parafraseando Ricœur (1999), o passado não pode ser mudado porque já passou; tampouco é possível inserir ou apagar dele detalhes ou acontecimentos - o que é possível é redefinir o sentido ou significado deles. Com este fim, ocorrem disputas entre os diferentes grupos que buscam "estabelecer/convencer/transmitir uma narrativa que possa chegar a ser aceita" (JELIN, 2002, p. 39). Estas lutas que visam outorgar o valor de verdade às versões da história e torná-las dominantes (LORENZ, 2002) envolvem usos (e abusos) do passado, conceito que se refere ao "papel que o passado deve desempenhar no presente" (TODOROV, 2000, p. 18).

Ao elegermos o passado recente como objeto de reflexão do dossiê que organizamos para esta edição da Revista Eletrônica da ANPHLAC, interessava-nos indagá-lo nesta chave particular. Para além da reconstituição de eventos ou processos históricos, nosso objetivo foi reunir textos que examinassem como o passado recente vem sendo interpelado para forjar determinadas identidades, legitimar ordens políticas, caracterizar inimigos, ressignificar personagens, justificar eleições, produções culturais e políticas públicas. Em suma, textos que contribuíssem para identificar o que do passado intervém em nossa vida cotidiana; que aspectos são atualizados por diferentes grupos sociais - e por quais meios - para explicar suas realidades; e que imagens, símbolos, modelos de ação se (re)constroem para dar sentidos à produção de ordens políticas, sociais, culturais e econômicas. 
A grande acolhida que teve o dossiê confirmou a tese de que se trata de um tema de crescente interesse na atualidade. Os artigos selecionados para publicação dão conta de diferentes contextos nacionais e adotam variados enfoques, abrangendo políticas governamentais, processos judiciais, produções culturais e movimentos sociais. Observam-se neles, também, diversas noções de história recente e de usos do passado, de acordo com as especificidades de cada objeto.

O dossiê tem início com três textos que se centram no contexto argentino para abordar as políticas transicionais, a conformação de certos atores coletivos em resposta ao terror de Estado e as ressignificações de acontecimentos emblemáticos da última ditadura militar em função de certos usos deste passado no presente. Em "La palabra de los perpetradores y el problema de la verdad en Argentina: entre el silencio y la justicia", Claudia Feld e Valentina Salvi indagam a relação entre a palavra dos perpetradores e a construção da verdade, demonstrando a falácia do postulado segundo o qual os repressores diriam a verdade se não fossem condenados por seus crimes. As autoras mostram o caráter historicamente produzido da categoria "verdade" e a prática permanente e ativa de construção que requereu que a justiça e outras mediações institucionais atuassem como plataforma ética contra o negacionismo e o silêncio da maioria dos perpetradores.

O artigo seguinte, "Del sentido histórico a la agenda ampliada: la experiencia de la Mesa de Trabajo por los Derechos Humanos de Córdoba, Argentina", de Ana Carol Solis, analisa a conformação e consolidação da Mesa de Trabalho pelos Direitos Humanos de Córdoba como uma instância interorganizacional inovadora que permitiu articular diferentes lutas e ampliar os sentidos associados ao marco dos direitos humanos. Para isso, a autora indaga os modos e sentidos com que as temporalidades habitam e atuam na ação militante e seus efeitos; e como se entrelaçam com a criação de processos de legitimação política e de atuação pública contestatória.

Por sua vez, Marcos Tolentino, em "La noche de los lápices e os usos públicos das memórias e das representações dos desaparecidos na Argentina (1976-1988)", analisa os 
processos históricos que resultaram no desaparecimento de um grupo de estudantes secundaristas na cidade de La Plata em setembro de 1976; a inclusão dos seus casos nas estratégias de denúncias dos familiares de desaparecidos e dos organismos de direitos humanos; e as políticas e representações elaboradas nos primeiros anos do retorno à democracia, entre 1984 e 1988. O autor mostra que este episódio emblemático dos crimes cometidos pela ditadura foi alvo de diferentes usos e ressignificações, em diálogo com as disputas em torno do passado recente e dos sentidos produzidos sobre a violência estatal e os desaparecimentos políticos.

Os três textos seguintes, centrados no caso chileno, debruçam-se sobre o uso de elementos de outros regimes autoritários durante a ditadura pinochetista e as formas de elaboração posteriores desta experiência repressiva por diferentes atores sociais. Em "Documentário e memória: os usos do testemunho em Nostalgia de la luz", Samuel Torres Bueno analisa os usos da memória nesta obra do cineasta Patricio Guzmán, que tem como mote as atividades de investigação do passado levadas a cabo por três grupos no deserto do Atacama: os astrônomos, os arqueólogos e as mulheres que almejam encontrar os restos dos seus familiares desaparecidos pela ditadura encabeçada por Augusto Pinochet. Interessado em observar os usos dos depoimentos e as práticas memorialísticas realizadas pelo documentário, o autor conclui que, para além de denunciarem os horrores da ditadura, os testemunhos também são empregados com vistas a impulsionar modificações no tempo presente e elaborar projetos de futuro.

A seguir, Lays Corrêa da Silva, em "O historiador Gonzalo Vial e a construção do Marco Político do Informe Rettig (1991)”, examina detalhadamente a narrativa utilizada na parte deste documento que se dedica aos eventos anteriores ao golpe de Estado de 1973. A autora reconhece ali a influência da teoria de Vial segundo a qual a ruptura da democracia no Chile se deu a partir da "quebra de consensos" - argumento que conduz à ideia de inevitabilidade do golpe. Assim, o texto enfoca o papel do historiador na construção de uma memória oficial do passado recente durante o governo de Patricio Aylwin, quando houve uma busca pela "reconciliação nacional" no processo de transição democrática. 
No último texto deste bloco dedicado ao Chile, intitulado "A hispanidade reivindicada: Pinochet e a apropriação do franquismo no Chile (1973-1975)", André Mateus Pupin inova ao se centrar não em como a ditadura de Pinochet foi recordada e representada posteriormente, mas em como ela própria se apropriou de seu passado recente para justificar ações políticas e culturais. $\mathrm{O}$ autor recorre a diferentes periódicos para demonstrar que a ditadura chilena recuperou e promoveu elementos do repertório associado à ditadura do espanhol Francisco Franco, apropriando-se dos valores conservadores da hispanidade para opor-se ao comunismo e à secularização e apagar as contradições e violações aos direitos humanos de seu governo.

A busca por legitimação política e o papel da imprensa na reatualização do passado também são abordados na sessão seguinte do dossiê, dedicada ao México. Em "Transição à democracia e os usos do passado recente para a legitimação de um novo regime político no México", Larissa Jacheta Riberti analisa o processo de transição à democracia à luz das mudanças políticas e institucionais e da atuação dos movimentos sociais mexicanos em fins do século XX. A autora associa a vitória de Vicente Fox nas eleições de 2000 à sua capacidade de utilizar as demandas por verdade, memória e justiça para construir uma plataforma política e uma coalização entre diferentes setores ideológicos. Porém, contrariando as expectativas, a chegada de Fox ao poder não foi capaz de consolidar a transição ou configurar uma democracia sólida, como conclui Riberti.

O artigo seguinte, escrito por José Antonio Ferreira da Silva Júnior, também enfoca o contexto da transição mexicana - desta vez, debruçando-se sobre o campo intelectual. Intitulado "O discurso intelectual sobre o passado em Nexos e Vuelta na transição democrática mexicana (1982-1992)", o texto se centra nas duas maiores publicações culturais do período para demonstrar que os grupos intelectuais reunidos em torno delas fomentaram discussões sobre a conjuntura política por meio de temas históricos e visões sobre o passado nacional. O autor argumenta, com base nos escritos de três historiadores ligados às revistas em questão - Héctor Aguilar Camín, Enrique Florescano e Enrique Krauze - que tais debates conduziram a 
polêmicas sobre a "história oficial" e a revisão historiográfica empreendida nas últimas décadas do século XX.

Os dois textos que fecham o dossiê, de autoria de Caroline Drummond e Pâmela Resende, trazem à tona conexões entre Cuba e Estados Unidos na segunda metade do século XX. Em "Revolução Cubana, literatura e homossexualidade: disputas pela memória de Virgilio Piñera em Mariel - Revista de Literatura y Arte (1983-1985)", Drummond analisa esta revista fundada em Miami por escritores cubanos exilados, defendendo que seu projeto editorial constituiu uma oposição política ao governo de Fidel Castro ao confrontar memórias oficiais e dar visibilidade às perseguições aos dissidentes, violações de direitos humanos e prisões políticas levadas a cabo na ilha. Para abordar a problemática da relação do regime com os intelectuais, a autora se centra na seção "Confluencias" da revista, que, conforme argumenta, estabelecia um "contra-cânone" combativo da literatura cubana, com foco no escritor Virgilio Piñera.

Já Pâmela Resende, em “A batalha entre a liberdade e a tirania: Revolução Cubana, guerra de guerrilhas e o desenvolvimento da Doutrina de Contrainsurgência norte-americana nos anos 1960", analisa a construção e o desenvolvimento das políticas estadunidenses para a América Latina a partir da década de 1960, a fim de verificar em que medida elas foram influenciadas pela Revolução Cubana e por outros movimentos guerrilheiros. A autora demonstra que a criação de programas de ajuda externa e o desenvolvimento da Doutrina de Contrainsurgência, durante o governo de John F. Kennedy, foram estratégias adotadas com vistas a conter o avanço das ideias comunistas na região, que ganharam força após 1959.

A inclusão deste texto sobre os Estados Unidos no dossiê se justifica pela forte intervenção deste país nos assuntos internos na região, com vistas a minar a perspectiva revolucionária aberta pela Revolução Cubana. Por meio de pressões diplomáticas, financeiras e políticas, bem como do patrocínio direto aos golpes de Estado e aos governos militares, os Estados Unidos, em aliança com setores da elite local, contribuíram para o desfecho trágico e 
traumático dos projetos revolucionários que desafiaram o status quo durante a chamada Guerra Fria interamericana (HARMER, 2011).

Como podemos depreender pela amostra de textos reunidos no dossiê, a história recente trabalha com referenciais e periodizações variáveis, de acordo com as especificidades dos processos locais, nacionais e regionais. Se nos casos chileno e argentino - aos quais poderíamos somar o brasileiro, que não foi abarcado devido ao fato de a revista não publicar estudos que versam exclusivamente sobre este país -, as últimas ditaduras militares e os processos imediatamente anteriores aparecem como marcos dificilmente contornáveis; nos casos cubano e mexicano, os parâmetros são necessariamente distintos. Não obstante, deparamo-nos com temas e problemáticas comuns, que apontam para tendências nos estudos sobre o passado recente: os processos de transição democrática, considerados sob o prisma das lutas por verdade, memória e justiça, bem como dos dilemas e obstáculos que dificultam sua concretização; o papel dos intelectuais na conformação de histórias oficiais ou na revisão de seus pressupostos; e a influência de experiências revolucionárias ou autoritárias no imaginário e na ação política de atores de esquerda e de direita. Fica claro, portanto, que a questão central deste campo de estudos é a da disputa pelos sentidos deste "passado que não passa".

Além do dossiê, a presente edição da Revista Eletrônica da ANPHLAC inclui as seções de artigos livres e resenhas. A primeira abrange quatro textos sobre temáticas diversas, que dão conta de importantes debates historiográficos e trajetórias intelectuais nas Américas. No primeiro deles, intitulado "Do gradualismo negro ao Sonho Americano: a formação do conservadorismo negro nos Estados Unidos", Flávio Thales Ribeiro Francisco, analisa a linhagem histórica de conservadores negros na cultura política estadunidense. $\mathrm{O}$ autor se centra nas trajetórias de figuras como George Schuyler, Booker T. Washington e Thomas Sowell para demonstrar que, ao longo da história, ocorreram mudanças nas abordagens de intelectuais e lideranças negras conservadoras associadas às circunstâncias políticas.

$\mathrm{O}$ artigo seguinte, “A América Latina em disputa: História e historiografia de uma polêmica", de Valdir Donizete dos Santos Junior, discute a circulação e os significados da ideia 
de "América Latina" desde sua formulação em meados do século XIX até a atualidade. O autor busca compreender, em perspectiva histórica, o processo de construção e as diversas apropriações do termo, tanto como artefato de projetos imperiais, quanto como instrumento de defesa identitária e geopolítica dos países hispano-americanos frente às pretensões expansionistas dos Estados Unidos. Além disso, examina as diferentes concepções historiográficas que têm balizado as discussões acerca dessa problemática.

Já "Diálogos epistolares e edição: intercâmbios intelectuais entre Brasil e Argentina na correspondência de Ricardo Levene e Pedro Calmon", de Nayara Galeno do Vale, enfoca as relações estabelecidas pelos intelectuais Ricardo Levene e Pedro Calmon na década de 1930, por ocasião das iniciativas de aproximação entre os governos de seus respectivos países: Argentina e Brasil. A autora utiliza como fontes principais as correspondências trocadas entre os dois intelectuais e observa que o diálogo entre eles esteve centrado em dois empreendimentos editoriais resultantes de convênios que visavam à cooperação intelectual entre Brasil e Argentina: a Biblioteca de Autores Brasileiros traduzidos ao castelhano e a Coleção Brasileira de Autores Argentinos.

No último artigo livre, intitulado "Algumas considerações em torno ao imbroglio Posada: quando as imagens não ilustram os textos", Natally Vieira Dias aborda a controversa questão das relações do artista mexicano José Guadalupe Posada com a política. Por meio da análise de algumas de suas gravuras publicadas na imprensa, a autora busca matizar as visões dicotômicas que o colocam ora como revolucionário e precursor da Revolução Mexicana, ora como reacionário e porfirista. Dias desconstrói a visão de um Posada porfirista e "surdo" aos anseios e propostas dos revolucionários e argumenta que o gravurista desenvolveu um discurso próprio, crítico, expresso por meio de uma linguagem e uma estética específicas, capazes de interpelar as classes populares.

A presente edição se encerra com resenhas que têm por objeto dois dos processos políticos mais revisitados do século XX sul-americano: o peronismo na Argentina e o governo da Unidade Popular no Chile. Intitulada "Transformações e permanências do movimento 
peronista na Argentina", a resenha de Raquel Lanzoni examina a edição de 2019 de Los deseos imaginarios del peronismo, do filósofo e historiador Juan José Sebreli, originalmente publicada em 1983. Tal como aponta a autora, na nova versão, Sebreli inseriu dois elementos de análise e discussão substanciais para a compreensão do cenário político argentino no tempo presente: o menemismo e o kirchnerismo, vistos como continuações do peronismo.

Por fim, no contexto do $50^{\circ}$ aniversário da chegada do marxista Salvador Allende à presidência do Chile, Eduardo Dianna resenha a obra Éramos iglesia... en medio del Pueblo: El legado de los Cristianos por el Socialismo en Chile 1971-1973, do teólogo Michael Ramminger, publicada na Alemanha em 2019 e traduzida no mesmo ano para o espanhol. O livro busca reconstituir a experiência histórica do movimento Cristãos pelo Socialismo durante seu curto período de atuação, inscrito nos anos da Unidade Popular chilena, valendo-se, para tal, de cartas, declarações públicas e entrevistas.

Publicar esta edição na atual conjuntura brasileira, em que proliferam revisionismos, negacionismos e ataques ao conhecimento histórico que reatualizam marcos interpretativos impostos pelas ditaduras da segunda metade do século XX, reveste-se de especial significado. Embora o dossiê não inclua nenhum estudo de caso correspondente ao Brasil, estamos convencidas de que as perguntas, reflexões e alternativas exploradas pelos autores e pelas autoras são de grande valia para pensar intervenções no presente e alternativas de futuro, tanto em nível local como regional. Em um momento em que somos interpelados/as pelos indivíduos e coletivos que buscam um acerto de contas com o passado e que nos damos conta da dimensão ética e política de nossos temas de estudo, urge retomar uma clássica questão: para que serve a história?

\section{Bibliografia}

ACEVES, José. Historia oral. México: Instituto Dr. José María Luis Mora, 1993. 
FRANCO, Marina. La historiografía de la historia reciente del Cono Sur. In: ÁGUILA, Gabriela et al. (Org.). La historia reciente en Argentina. Balance de una historiografía pionera en América Latina. Buenos Aires: Imago Mundi, 2018, p. 175-195.

FRANCO, Marina; LEVÍN, Florencia. El pasado cercano en clave historiográfica. In:

FRANCO, Marina; LEVÍN, Florencia (Org.). Historia reciente: perspectivas y desafíos de un campo en construcción. Buenos Aires: Paidós, 2007, p. 31-66.

HARMER, Tanya. Allende's Chile and the Inter-American Cold War. Chapel Hill: The University of North Carolina Press, 2011.

HARTOG, François. Regimes de historicidade: presentismo e experiências do tempo. Belo Horizonte: Autêntica, 2014.

HALBWACHS, Maurice. Los marcos sociales de la memoria. España: Anthropos, 2004.

HALBWACHS, Maurice. La memoria colectiva. Buenos Aires: Miño y Dávila Editores, 2001.

HUYSSEN, Andreas. En busca del futuro perdido. Cultura y memoria en tiempos de globalización. Buenos Aires: Fondo de Cultura Económica de Argentina, 2001.

JELIN, Elizabeth. Los trabajos de la memoria. Madrid; Buenos Aires: Siglo XXI Editores, 2002.

LORENZ, Federico. ¿De quién es el 24 de marzo? Las luchas por la memoria del golpe de 1976. In: JELIN, Elizabeth (Org.). Las conmemoraciones: las disputas en las fechas "infelices". Madrid: Siglo XXI Editores, 2002, p. 53-100.

PITTALUGA, Roberto. El pasado reciente argentino: interrogaciones en torno a dos problemáticas. In: BOHOSLAVSKY, Ernesto et al. (Org.). Problemas de historia reciente del Cono Sur, vol. 1. Buenos Aires: Prometeo Libros; Universidad Nacional Sarmiento, 2010, p. 23-35.

POLLAK, Michael. Memoria, Olvido y Silencio. La producción social de identidades frente a situaciones límites. La Plata: Al margen, 2006.

PORTELLI, Alessandro. Lo que hace diferente a la historia oral. In: SCHWARZSTEIN, Dora (Org.). La historia oral. Buenos Aires: CEAL, 1991, p. 36-51. 
RICCEUR, Paul. La lectura del tiempo pasado: memoria y olvido. Madrid: Arrecife Producciones, 1999.

TODOROV, Tzvetan. Los abusos de la memoria. Barcelona: Paidós, 2000. 